\title{
Ensino de Física para surdos: um experimento mecânico e um eletrônico para o ensino de ondas sonoras ${ }^{+*}$
}

\author{
Deise Benn Pereira Vivas ${ }^{1}$ \\ Mestranda em Ensino, Filosofia e História da Ciência - UFBA \\ Elder Sales Teixeira ${ }^{2}$ \\ Juan Alberto Leyva Cruz ${ }^{3}$ \\ Departamento de Física - Universidade Estadual de Feira de Santana \\ Feira de Santana - BA
}

\section{Resumo}

Este trabalho se insere na temática sobre o papel das Tecnologias Assistivas na compreensão conceitual e na promoção da inserção social de estudantes surdos. São apresentadas duas versões (mecânica e eletrônica) de um experimento didático desenvolvido pelos autores para o ensino de ondas sonoras, voltado primordialmente para estudantes surdos do Ensino Médio. Inicialmente, é feito um breve histórico da educação para surdos desde a antiguidade, seguida de uma discussão teórica sobre a física da voz. Na sequência, são apresentadas as duas versões do experimento com seus detalhes técnicos e o processo de elaboração dos mesmos, bem como, uma discussão teórica acerca de uma perspectiva para uso didático destes experimentos, orientado por uma visão vigotskiana. Ao final, são feitas considerações acerca do potencial uso didático do experimento visando a inclusão dos alunos surdos em classes regulares, visto que se trata de experimentos ainda não avaliados em situações reais de sala de aula.

Palavras-chave: Ensino de Física para surdos; Ondas Sonoras; Tecnologias Assistivas.

\footnotetext{
${ }^{+}$Physics teaching for deaf: a mechanical and electronic experiment for teaching of sound waves

* Recebido: dezembro de 2015.

Aceito: novembro de 2016.

1 E-mail: deisevivas@gmail.com

2 E-mail: eldersate@gmail.com

${ }^{3}$ E-mail: jalbertoleyva@yahoo.com.br
} 


\begin{abstract}
This work is about the role of assistive technology on conceptual understanding and social integration of deaf students. The authors present two versions (mechanical and electronic) of a didactic experiment, developed by them, to teach sound waves for deaf students. A brief history of education for deaf from antiquity, followed by a theoretical discussion about the physics of voice, is made. Two versions of the experiment with their technical details and the process of preparing, as well as a theoretical discussion about the prospect for didactic use of this experiment, guided by a vigotskian conception are presented. Finally, the authors make considerations on the potential use of this experiment aiming the inclusion of deaf students.
\end{abstract}

Keywords: Physics teaching for deaf; Sound waves; Assistive technologies.

\title{
I. Introdução
}

O ensino para surdos tem sido muito discutido atualmente entre os profissionais de educação (PEREIRA, 2008; SACKS, 2010; GOLDFELD, 2002; MOURA, 2000), sobretudo pelas dificuldades enfrentadas por professores quando se deparam com a presença de alunos surdos em suas salas de aula. Soma-se às dificuldades, a ausência de atenção dos livros didáticos para com alunos surdos no tratamento de assuntos tais como ondas sonoras. Dentre as possibilidades para se contrapor às consequências sociais causadas pela surdez, está o uso de Tecnologias Assistivas, que tratam de recursos e serviços para a solução de problemas de acessibilidade do aluno na escola, através das quais se pode conhecer e criar novas alternativas para a comunicação, escrita, mobilidade, leitura, utilização de materiais pedagógicos, compreensão etc., para que o aluno possa participar e atuar positivamente nas várias atividades, substituindo a sua função de espectador pela função de ator fomentando, assim, a sua interação social na escola. Entretanto, há poucos estudos que investigam o papel das Tecnologias Assistivas no ensino de física. Desta forma, usando a concepção de aprendizagem de Vigotski $(2000 ; 2001)$ como suporte teórico, em particular sua teoria da compensação que não enfatiza apenas o aspecto negativo que a deficiência apresenta, mas também a eficiência das estratégias pedagógicas para que o problema seja superado, o presente trabalho pretende contribuir com esta temática discutindo o papel de um experimento desenvolvido especificamente para ser utilizado como uma forma de Tecnologia Assistiva para o ensino das ondas sonoras destinado à inclusão dos alunos surdos.

A realidade enfrentada pelas pessoas com deficiência, ainda não é totalmente esclarecida para a maioria da população. Segundo o Censo 2000 (IBGE, 2011) o número de surdos no 
Brasil era de 166.400 , sendo 80 mil mulheres e 86.400 homens e cerca de 900 mil pessoas declararam ter grande dificuldade permanente de ouvir. Embora no Brasil existam algumas leis voltadas para a necessidade das pessoas com deficiência, como o Decreto $\mathrm{n}^{\circ} 914$ que institui a Política Nacional para a Integração da Pessoa Portadora de Deficiência (BRASIL, 2002) e a Lei Federal $n^{\circ} 10.098 / 00$ que estabelece normas gerais sobre a acessibilidade das pessoas com deficiência ou com mobilidade reduzida (BRASIL, 2002), entre outras, "essas leis são implantadas lentamente e muitas vezes são ignoradas por parte da sociedade e até mesmo por alguns órgãos públicos" (HONORA; FRIZANCO, 2008: 20).

No que tange à educação, a segregação e/ou exclusão ainda são notáveis. Apesar de estar declarado na Constituição Federal de 1988 que a educação é direito de todos e dever do Estado e que a escola, por sua vez, tem como obrigação atender a todos, seguindo os princípios de igualdade, acesso e permanência, liberdade de aprender e ensinar (BRASIL, 1988), o que se percebe de forma geral são reclamações de professores e dirigentes acentuando que não estão preparados para trabalhar com alunos com deficiência. Ou seja, algumas escolas e professores não disponibilizam recursos e metodologias que efetivamente atendam às especificidades destes estudantes (GALVÃO, 2009).

Ao propor sua política oficial de inclusão - além dos documentos já citados há o decreto $n^{\circ} 3.956 / 2001$ que afirma que as pessoas com deficiências possuem os mesmos direitos e liberdades que as outras e a lei $n^{\circ}$ 10.436/02 que reconhece a LIBRAS (Língua Brasileira de Sinais) como meio legal de comunicação e expressão, entre outras coisas - o governo brasileiro parece ter resumido o problema em apenas oferecer cursos de LIBRAS aos professores e/ou contratar intérpretes para os alunos surdos em sala de aula. Porém o intérprete contratado nada (ou pouca coisa) pode fazer se na escola onde trabalha há uma predominância de ações voltadas para crianças ouvintes. Outro problema consiste no fato de que uma sala de aula possui apenas um intérprete para todas as disciplinas e este não possui formação acadêmica capaz de dar conta de todos os campos do saber. Assim, por não possuir o mesmo conhecimento do professor, o intérprete traduz apenas o que ele entendeu da explicação do professor daquele determinado assunto, podendo haver muita perda de significado nesta tradução.

Essas dificuldades vivenciadas tornam urgente a construção de novas possibilidades e caminhos para que o docente seja capaz de apropriar-se dos recursos de acessibilidade e, consequentemente, aprimorar sua formação para que possa adequar sua prática com as necessidades do aluno surdo.

Dentre as possibilidades para neutralizar as consequências sociais causadas pela ineficiência orgânica, está o uso de Tecnologias Assistivas, cujo principal objetivo é dar a possibilidade para que a pessoa possa construir sua independência motora, auditiva, mental ou de qualquer outro tipo de deficiência. Segundo o Comitê de Ajudas Técnicas (CAT), uma instância de estudos e de proposição de políticas públicas da Secretaria Especial dos Direitos Humanos da Presidência da República (SEDH/PR), Tecnologia Assistiva significa: 
Uma área do conhecimento, de característica interdisciplinar, que engloba produtos, recursos, metodologias, estratégias, práticas e serviços que objetivam promover a funcionalidade, relacionada à atividade e participação de pessoas com deficiência, incapacidade ou mobilidade reduzida, visando sua autonomia, independência, qualidade de vida e inclusão social (CAT, 2007, p. 3).

Dentro desta perspectiva, este trabalho versa sobre o papel das Tecnologias Assistivas na compreensão conceitual e na promoção da inserção social de alunos surdos. As Tecnologias Assistivas aqui referidas constam de duas versões (uma mecânica e uma eletrônica) de um experimento didático, elaborado pelos autores deste trabalho, para tratar do tema ondas sonoras de modo a permitir que o aluno surdo (e também o ouvinte) possa ter a percepção visual das ondas a partir da produção de som da voz humana emitida pelo próprio aluno no referido aparato experimental. Discute-se, assim, o potencial didático do referido experimento em termos da sua função no processo de aprendizagem com ênfase nos seus aspectos sociointeracionistas à luz da teoria compensatória desenvolvida por Vigotski, que será brevemente explanada mais adiante.

\section{Um breve histórico da educação para surdos}

Durante muito tempo, dizia-se que a pessoa surda não possuía nenhuma serventia (BERTHIER, 1984, apud NASCIMENTO, 2006, p. 257). Atualmente, de modo geral, o surdo é considerado como parte integrante de uma comunidade surda que possui uma cultura e uma identidade próprias. Essa mudança de concepção não aconteceu de forma arbitrária, mas foi fruto de um conjunto de situações políticas, sociais e econômicas que nortearam as diretrizes implementadas na educação dos surdos em diferentes tempos.

As diferentes abordagens, independente de seus benefícios ou malefícios, fazem refletir sobre como encontrar o melhor método que favoreça a educação dos surdos e para que os mesmos se desenvolvam plenamente como sujeitos integrantes de uma sociedade. A história da educação dos surdos é um tema atual, visto que vários professores se deparam com um aluno surdo em sua classe. Entretanto, para falar sobre a surdez é necessário entender como o surdo tem sido visto através da história e as dificuldades encontradas para se constituir como sujeito.

$\mathrm{Na}$ Antiguidade, acreditava-se que os surdos eram aberrações. Em Esparta, as crianças que nasciam surdas eram condenadas a sofrer a mesma morte que as crianças que nasciam com retardo ou com deformidades: eram asfixiadas ou jogadas de um precipício nos rios ou, ainda, tinham suas gargantas cortadas. Para tais sociedades antigas, não havia motivos para poupar as vidas dos surdos, uma vez que aquelas não poderiam ser beneficiadas com o trabalho destes (BERTHIER, 1984, apud NASCIMENTO, 2006).

O primeiro passo para a educação dos surdos foi dado no século XIV quando o escritor e advogado Bartolo Della D’Acona, fez a primeira referência à possibilidade de instruir os surdos por meio da língua de sinais ou da linguagem oral. Isto se deveu apenas às implicações 
legais que a comunicação verbal ou a língua de sinais acarretavam, pois até então os surdos não poderiam dar continuidade à herança da família (MOURA, 2000).

Outros grandes nomes foram importantes na construção desta história cheia de equívocos e desencontros, como por exemplo, Charles-Michael de L'epeé que teve grande importância na construção de uma nova visão na educação dos surdos, implantando uma nova forma de trabalho que deu reconhecimento à língua de sinais; Jean-Marc Itard, um renomado otorrinolaringologista, que acreditava que a surdez deveria ser erradicada para que o Surdo pudesse ter acesso ao conhecimento; Alexander Graham Bell, grande defensor do oralismo, entre outros (GOLDFELD, 2002).

Durante muito tempo o método oralista, baseado na correção da fala, foi empregado em detrimento da língua de sinais. O objetivo dessa concepção de educação para os surdos era inserir os mesmos na sociedade, integrar a "anormalidade" (a surdez) à "normalidade" (capacidade de ouvir), para isso o surdo tinha que se adaptar à língua majoritária: a língua do ouvinte (GOLDFELD, 2002).

No começo do século XX verificam-se os primeiros indícios do fracasso do oralismo. Após o Congresso de Milão, um inspetor foi enviado para alguns países com o objetivo de verificar o desenvolvimento dos alunos surdos que foram educados de acordo com este método e percebeu que os mesmos não estavam preparados para assumir grandes funções no mercado de trabalho. Possuíam profissões básicas e a sua linguagem era ininteligível, compreendida apenas por quem tinha um convívio próximo ao surdo (MOURA, 2000). O fracasso desse sistema está no fato de que foi dispensado muito tempo na tentativa de oralizar o surdo e, portanto, a sua educação geral foi deixada em segundo plano. Ensinar os surdos a falar; essa é verdadeiramente uma tarefa que demanda dedicação, pois requer, para que haja alguma esperança de êxito, muitos anos do mais intensivo e árduo treinamento, com um professor trabalhando com um só aluno (SACKS, 2010, p. 33). Assim, no final do processo, o indivíduo era considerado com dupla deficiência: auditiva e mental. Segundo Vigotski (1997), a principal causa do fracasso desse método é devido à falta de estímulo que a língua falada proporciona na criança, tornando-se algo inconsciente.

Deste modo, para Vigotski (1997), o que inibe o desenvolvimento do indivíduo surdo não é a deficiência em si, mas as consequências sociais que ela acarreta. Assim, para que o surdo possa desenvolver-se adequadamente, se faz necessário um trabalho educacional voltado para a compensação do déficit e não para a correção da surdez. Permanece, então, a questão da importância do desenvolvimento dos recursos didáticos, pois estes materiais têm de ser significativos para os alunos com as mais diversas capacidades. Vale ressaltar que a teoria da compensação elaborada por Vigotski não tem como finalidade extinguir a ineficiência auditiva, mas superar as dificuldades que a mesma cria. 


\section{Noções sobre a física da voz}

Uma forma interessante de ensinar, discutir ou refletir sobre as ondas mecânicas é estudando a Física da própria voz. Para entender estes processos físico-biológicos é necessário abordar a física das ondas mecânicas. As ondas mecânicas podem ser definidas como perturbações ou distúrbios que se propagam em meios materiais. Exemplos destes tipos de ondas no dia a dia são: as ondas em cordas (geradas pelas cordas dos instrumentos musicais); ondas sonoras (importantes na comunicação entre humanos através da voz ou o som da passagem do fluxo de ar por fendas); ondas na água (ondas do mar, ou aquelas produzidas ao se atirar uma pedra num lago).

A importância destas ondas nasce justamente de sua principal característica, que é o fato delas transmitirem energia. Isso confere a elas a capacidade de serem utilizadas na medicina tanto como ferramentas de diagnósticos como na terapêutica. Além disso, servem como princípio físico de comunicação e orientação entre indivíduos de uma mesma espécie incluindo os seres humanos.

As ondas, quanto à sua direção de propagação, podem ser de dois tipos: transversais que ocorrem quando a perturbação é perpendicular à direção de propagação da onda, como o caso das ondas produzidas nas cordas; longitudinais - que ocorrem quando o distúrbio é dado na mesma direção de propagação da onda, como no caso das ondas de som.

Usando como fonte principal o livro de Duran (2011), vamos fazer uma breve discussão sobre o processo de produção da voz humana. Para construir nosso modelo físico, imaginemos o caso de ondas estacionárias longitudinais de variação de pressão (como no caso da voz) geradas no interior de um tubo de comprimento $\mathbf{L}$ com uma de suas extremidades fechada e a outra aberta (como no caso do trato vocal). Na extremidade fechada a onda deverá ter amplitude máxima (existência de um antinó), e na extremidade aberta, a amplitude é nula (presença de um nó). Nesta situação, os comprimentos de onda são dados por

$$
\lambda_{n}=\frac{4 L}{n} \quad n=1,3,5,7, \ldots
$$

Sendo que o número harmônico $n$ é um número ímpar, e as frequências destes harmônicos podem ser obtidas por

$$
f_{n}=\frac{v}{\lambda_{n}}=\frac{n v}{4 L}
$$

A frequência para $n=1$ é igual a $\mathrm{f}_{1}=v / 4 \mathrm{~L}$, é chamada de frequência fundamental.

De acordo com nosso modelo físico, o trato vocal é um tubo de ar fechado em uma das extremidades, com um comprimento aproximado de $17 \mathrm{~cm}$, apresentando uma frequência ressonante dominante em torno de $500 \mathrm{~Hz}$. É bem conhecido na literatura que num homem adulto, as pregas vocais têm de $17 \mathrm{~mm}$ a $23 \mathrm{~mm}$ de comprimento, e de $12,5 \mathrm{~mm}$ a $17 \mathrm{~mm}$ em uma mulher adulta. Elas podem ser comprimidas em $3 \mathrm{~mm}$ ou $4 \mathrm{~mm}$ pela ação dos músculos da laringe. A 
voz de homem adulto ressona em torno de $125 \mathrm{~Hz}$ e a de uma mulher adulta em torno de $250 \mathrm{~Hz}$; já em crianças esta frequência fica próxima de $300 \mathrm{~Hz}$.

Uma das características dos seres humanos que lhes permitem interagir com o meio ao seu redor é sua capacidade de responder a estímulos sonoros e produzir ondas sonoras. O primeiro em essência é o sentido da audição humana, que está relacionado com a capacidade que o ouvido apresenta de perceber uma onda sonora que é caracterizada, dentre outras coisas, pela sua frequência (f) e seu comprimento de onda $(\lambda)$ e que se propaga no interior de um meio elástico e, no interior do ouvido, passa por um processo de conversão até chegar ao cérebro onde é decodificada.

A produção de ondas sonoras ou da voz humana acontece no trato vocal. Uma característica peculiar da voz é sua natureza multi-harmônica e o fato da amplitude diminuir com o aumento da frequência. É conhecido que a faixa de frequência do som audível pelos seres humanos é de $20 \mathrm{~Hz}$ até $20 \mathrm{kHz}$, aproximadamente. Logo, conhecendo que a velocidade do som no ar é de $343 \mathrm{~m} / \mathrm{s}$, o comprimento de onda da voz humana varia desde $1,7 \mathrm{~cm}$ até $170,0 \mathrm{~cm}$.

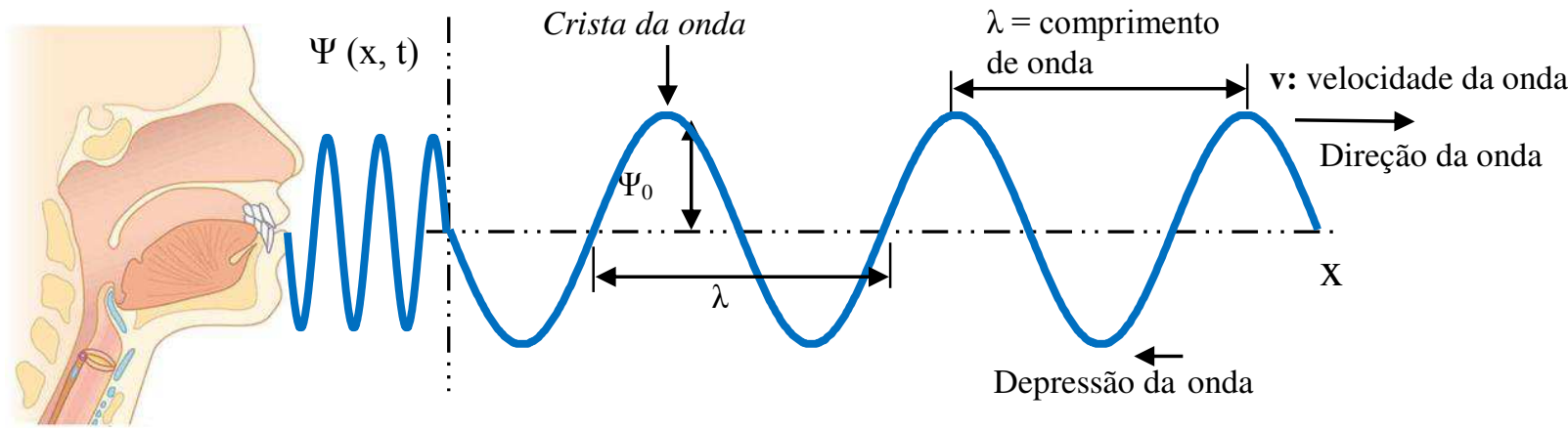

Fig. 1 - Representação esquemática da voz por uma onda mecânica sonora mostrando suas principais partes, como as cristas e depressão, amplitude ( $\left.\Psi_{0 \mathrm{voz}}\right)$, o comprimento de onda ( $\lambda$ ) e a velocidade de propagação (v). Fonte: elaborada pelos autores.

Independentemente do idioma que uma pessoa fale, todas utilizam a mesma anatomia para produzir o som de sua voz. Podemos afirmar que a voz humana é uma onda sonora que ao mesmo tempo é uma onda mecânica longitudinal da variação de pressão no ar.

Na Fig. 1, mostramos uma representação esquemática da onda sonora da voz. A função deslocamento $\Psi_{\mathrm{voz}}(x, t)$ desta onda sonora pode ser representada matematicamente por uma equação periódica da seguinte forma

$$
\Psi_{\mathrm{voz}}(x, t)=\Psi_{0 \mathrm{voz}} \operatorname{sen}(\mathrm{kx}-\omega \mathrm{t})
$$

Sendo $\Psi_{0 \mathrm{voz}}$ o valor máximo da diferença da amplitude da pressão num pequeno volume do meio de propagação da onda e $\operatorname{sen}(\mathrm{kx}-\omega \mathrm{t})$ é o termo oscilatório, caracterizado pela vetor de onda $\mathrm{k}$, e a frequência de oscilação $\omega$.

A intensidade $I$ da onda sonora é definida como a potência média transmitida $\langle\mathrm{P}\rangle$, por unidade de área $A$, isto é 


$$
I=\langle P\rangle / A
$$

A potência média é a taxa média a qual as energias cinética e potencial são transmitidas pela onda sonora e pode ser calculada por

$$
P=\frac{1}{2} \rho A v w^{2} \Psi_{0 \mathrm{voz}}^{2}
$$

Logo, a intensidade pode ser calculada por

$$
I=\frac{P}{A}=\frac{1}{2} \rho v w^{2} \Psi_{0 \mathrm{voz}}^{2}
$$

Sendo que $\rho$ e v representam a densidade do meio e velocidade da onda, respectivamente.

Também é possível fazer uma análise da potência da voz humana. Considerando que a potência aproximada de uma pessoa falando normalmente é da ordem de $10^{-5} \mathrm{~W}$ e a área da boca da ordem de $10^{-3} \mathrm{~m}^{2}$, então podemos calcular que a intensidade (I) da voz é aproximadamente $I_{0}=10^{-2} \mathrm{~W} / \mathrm{m}^{2}$.

A resolução (menor valor de intensidade da onda sonora que uma pessoa normal pode detectar pelo ouvido) do ouvido é muito grande e depende da frequência do sinal; no caso de uma frequência de $440 \mathrm{~Hz}$, a resolução é da ordem de $10^{-10} I_{0}=10^{-12} \mathrm{~W} / \mathrm{m}^{2}$. Consequentemente, a faixa de intensidade permitida pela audição humana começa em $10^{-12} \mathrm{~W} / \mathrm{m}^{2}$ até $1 \mathrm{~W} / \mathrm{m}^{2}$, valores que correspondem ao som emitido por uma pessoa que fala em voz baixa e quando grita (voz alta). Os valores de intensidade da voz na faixa de (1 a 10)W/m² são capazes de induzir efeitos nocivos à saúde da pessoa, tais como dor nos ouvidos. Por outro lado, em geral, a intensidade $I$ do som pode ser analisada usando a intensidade sonora $\beta$, definida por:

$$
\beta=10 \cdot \log \left(\frac{I}{I_{0}}\right)(\mathrm{dB})
$$

Desta expressão podemos concluir que para valores próximos do limiar inferior $\left(10^{-12} \mathrm{~W} / \mathrm{m}^{2}\right)$ a intensidade sonora $\beta=0 \mathrm{~dB}$, já no limiar superior de $1 \mathrm{~W} / \mathrm{m}^{2}, \beta$ alcança valores de $120 \mathrm{~dB}$, que pode provocar efeitos adversos nas pessoas.

Do ponto de vista físico, a produção da voz humana pode ser explicada analisando o fluxo do ar que atravessa o trato vocal (filtro capaz de produzir vários tipos de harmônicos que compõem a voz) e que emerge dos pulmões. Como resultado, um conjunto limitado de sons individuais ou fonemas podem ser produzidos. Estes fonemas podem ser divididos em duas categorias, os sons sonoros e os mudos. Os primeiros são geralmente vogais e muitas vezes têm altos níveis de energia média e muitas frequências ressonantes diferentes ou formantes. Na maioria das vezes são gerados pelo ar proveniente dos pulmões que forçam as cordas vocais, provocando sua vibração de forma aproximadamente periódica, criando os impulsos de ar chamado de vibração glotal. A velocidade de vibração das cordas vocais determina o tom do som da voz produzida, isto também é conhecido na literatura como pitch. Posteriormente, o fluxo de ar passa pelo resto do trato vocal, onde ressona em algumas frequências. É bem conhecido que as 
mulheres e crianças apresentam vozes mais agudas do que os homens, como resultado de uma taxa maior de vibração durante o processo de produção de sons sonoros. Por outro lado, os sons mudos apresentam menor energia e maior frequência, e são normalmente consoantes em comparação com os sons sonoros. Uma característica peculiar que envolve a produção do som mudo ou não sonoro é que o ar é forçado através do trato vocal em um fluxo turbulento e é por esse motivo que durante este processo as cordas vocais não vibram, em vez disso, elas permanecem abertas até que o som é produzido. No som mudo não existe tom nem pulso glotal (DURAN, 2011).

Deste modo podemos afirmar que a vibração das cordas vocais, ou falta de vibração, é o processo principal na produção de diferentes tipos de voz. A forma do trato vocal é um fator importante que determina a produção da fala. Diferentes formas do trato vocal produzem vozes diferentes, ou sons ressonando a frequências ressonantes diferentes. O trato vocal forma as frequências do ar vibratório que viajam através dele, de modo que quando uma pesssoa fala, o trato vocal está constantemente em mudança de forma a uma taxa muito pequena para produzir diferentes sons os quais fluem juntos para criar uma palavra. Do mesmo modo que a caixa acústica do violão forma as notas musicais formadas pelo som das vibrações das cordas do violão. Desta forma podemos concluir que a voz nos seres humanos é produzida pela vibração das cordas ou pregas vocais localizadas na laringe e que produzem ondas sonoras que são ressonadas no trato vocal. Estes pulsos são modulados pelas ressonâncias do trato vocal, que no caso da voz humana estão no primeiro e segundo harmônico, e são chamadas de formantes vocais e podem ser modificadas pela ação de articuladores para gerar sons vocais distinguíveis, como as vogais. A voz também pode ser afetada pela quantidade de ar que sai dos pulmões e viaja atraves do trato vocal. Quanto maior for a massa de ar que atravessa o trato vocal, mais alto será o som da voz produzida.

Usando a equação (2) de nosso modelo físico, para um par de cordas vocais de comprimento $L$, tensão $\sigma$, e densidade $\rho$, a sua frequência de vibração natural, a partir da comparação com a frequência de uma corda normal, é dada por

$$
f=\sqrt{\frac{\sigma}{4 L^{2} \rho}}
$$

Desta equação podemos ver que o conteúdo harmônico da voz depende do comprimento em repouso, tensão e densidade das pregas vocais. Na fase da adolescência as pregas vocais se alongam, e a voz fica mais grave (pitch diminui). Também podemos ver da equação (8) que a frequência aumenta ao aumentar a tensão nas pregas vocais. A mudança de tensão nas pregas vocais (interna ou externa) permite a fonação com diferentes frequências. 

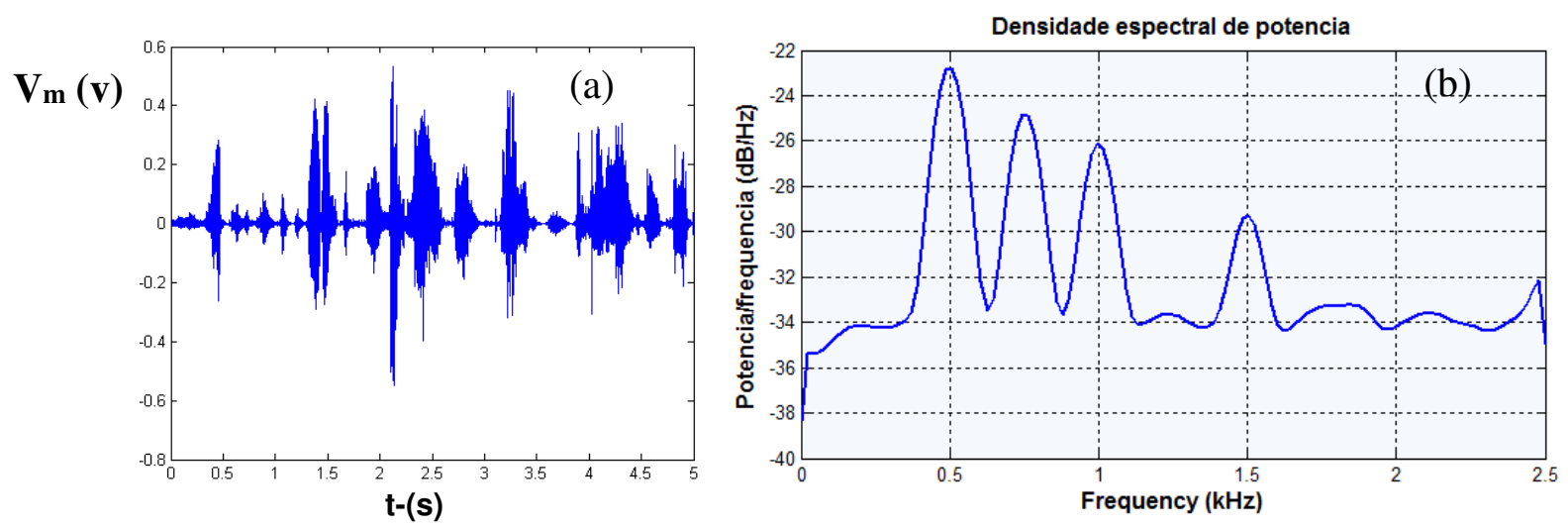

Fig. 2 - Em (a) a forma da onda sonora multiharmônica da voz medida experimentalmente, usando a porta de som de um computador; em (b) a densidade espectral de potência de uma onda mecânica da voz com frequência fl de ressonância de $500 \mathrm{~Hz}$, e outras harmônicas múltiplas tais como $650 \mathrm{~Hz}, 1000 \mathrm{~Hz}, 1500 \mathrm{~Hz}$ (3f1) e $2500 \mathrm{~Hz}(5 \mathrm{fl})$, mostrando a composição de frequências de uma onda mecânica como a da voz. Fonte: elaborada pelos autores.

Considerando um modelo simplificado do trato vocal de aproximadamente $17 \mathrm{~cm}$ de comprimento, com densidade de $1040 \mathrm{~kg} / \mathrm{m} 3$ e tensão de $12 \mathrm{kPa}$, para um valor de velocidade constante do som (v) de $343 \mathrm{~m} / \mathrm{s}$, o valor da frequência fundamental é de aproximadamente $500 \mathrm{~Hz}$. Na Fig. 2, mostra-se em (a) a forma da onda sonora multiharmônica da voz humana medida experimentalmente, usando a porta de som de um computador; em (b) observa-se a densidade espectral de potência de uma onda mecânica da voz com frequência de ressonância de $500 \mathrm{~Hz}$, e outras harmônicas múltiplas tais como $650 \mathrm{~Hz}, 1000 \mathrm{~Hz}, 1500 \mathrm{~Hz}$ (3f1) e $2500 \mathrm{~Hz}$ (5f1), mostrando a composição de frequências de uma onda mecânica como a da voz.

\section{Os Experimentos}

Apesar da Constituição Federal de 1988 declarar que a educação é direito de todos e dever do Estado e que a escola, por sua vez, tem como obrigação atender a todos, seguindo os princípios de igualdade, acesso e permanência, liberdade de aprender e ensinar (artigos 205 e 206) (HONORA, 2008, p. 29), o que se percebe é que algumas escolas e professores não disponibilizam recursos e metodologia que efetivamente respondam às especificidades dos estudantes com deficiência (GALVÃO, 2009), e, por conseguinte, sua metodologia não está contextualizada com a realidade sociocultural. Soma-se a isto a inadequação em geral dos livros didáticos, o que se constitui como um verdadeiro obstáculo na apropriação do conhecimento por parte do aluno surdo. Estes problemas surgiram da desconsideração da singularidade linguística dos surdos em sua especificidade viso-espacial. 
A inadequação dos livros didáticos de Física pode ser expressa na forma com que têm abordado o tema ondas sonoras. Sabemos que é trivial para uma criança ouvinte ter uma percepção sensorial deste assunto, o que contribui para uma compreensão dos conceitos acerca deste tema (como frequência, timbre, intensidade), pois a qualquer momento o professor, e até mesmo o livro, pode fazer uma alusão à experiência auditiva pela qual o aluno ouvinte já tenha passado. Porém, quando se trata de um aluno surdo isto não acontece dificultando ainda mais o entendimento. Ele necessita de outros mecanismos para atrelar o conhecimento teórico apresentado nos livros com a sua singularidade.

Por isso, tendo como base as teorias compensatórias de Vigotski, pensamos e projetamos um experimento ${ }^{4}$ cuja função pedagógica é dar oportunidade ao aluno surdo de ter uma experiência visual da onda mecânica sonora produzida pela sua própria voz. Este experimento foi elaborado em duas versões (mecânica e eletrônica) que serão descritos em seguida.

\section{IV.1 Versão Mecânica}

Na Fig. 3 é mostrado o dispositivo para visualizar a existência de diferentes configurações da onda sonora. $\mathrm{O}$ aparato ${ }^{5}$ é formado por uma caixa acústica feita de uma cabaça na qual foi cortada uma tampa e colocada uma pele de tambor. A mesma foi fixada com elástico. No extremo inferior da cabaça fez-se um corte diametral onde foi introduzida uma mangueira sanfonada, fixada com cola de silicone. $\mathrm{O}$ aparato é apoiado sobre um suporte de ferro.

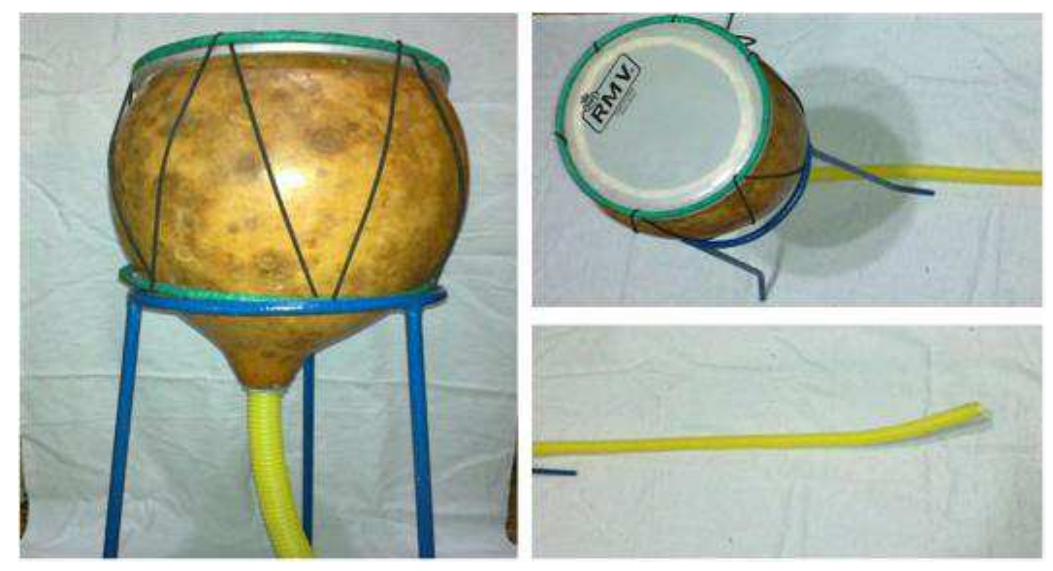

Fig. 3 - Dispositivo para permitir que se possa ter uma percepção visual de uma onda sonora. Fonte: elaborada pelos autores.

Foram testados alguns grãos para serem colocados na superfície da pele (areia, açúcar, farinha) para que, ao ser emitido um som de voz humana na extremidade da mangueira sanfonada, a onda sonora seja transmitida ao longo da mangueira fazendo com que a pele vibre e

\footnotetext{
4 Os autores deste trabalho agradecem a José Ivanilton de Jesus Portela pela contribuição na elaboração deste aparato experimental.

${ }^{5}$ Este protótipo foi inspirado numa montagem similar encontrada em Valadares (2002).
} 
assim o material escolhido (açúcar) ${ }^{6}$ forme a configuração da onda correspondente à frequência emitida. Ao mudarmos a frequência a configuração também muda, como é esperado, pois cada formato de onda corresponde a uma frequência diferente. A proposta do experimento é fazer com que os alunos (surdos e ouvintes) possam emitir som a partir da sua própria voz, perceber a configuração correspondente, identificar as diferenças de configuração em relação aos sons emitidos pelos demais colegas e ter uma experiência visual da sua própria voz. A partir de então, várias discussões conceituais podem ser feitas com a intervenção do professor.

Embora este experimento ainda não tenha sido objeto de investigação em uma situação real de sala de aula, uma versão preliminar do mesmo foi utilizada de forma exploratória em uma dupla de alunas surdas (ambas tinham concluído o ensino médio sem estudar ondas sonoras) de um curso de LIBRAS, cuja única aluna ouvinte é a primeira autora do presente trabalho. A primeira reação das alunas surdas ao perceberem visualmente as ondas sonoras decorrentes das suas próprias vozes foi de encanto e surpresa. Mesmo já tendo alguma experiência com a vibração do aparelho celular ou com vibração na parede proporcionada pela música em uma boate, elas não tinham tido a oportunidade de ver uma imagem que representa a configuração da onda provocada pela sua própria voz. Ao ver a mudança na imagem devido à mudança de frequência e à vibração das partículas de açúcar, elas conseguiram ter uma percepção sobre as noções de altura e timbre. Resultados parciais deste estudo exploratório foram apresentados em (VIVAS, 2012).

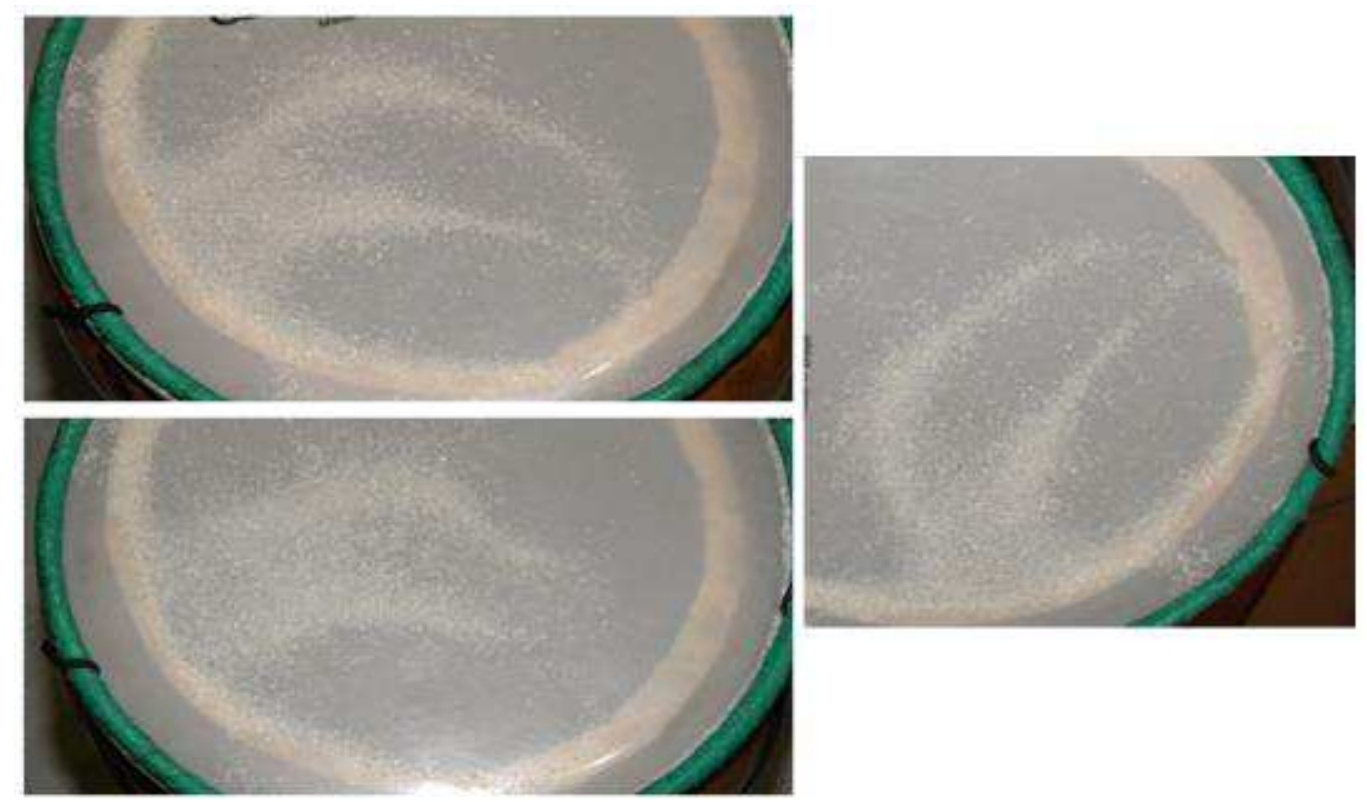

Fig. 4 - Fotografia da configuração da onda sonora formada pelas vibrações do grão de açúcar ao ser produzido o som de voz humana. Fonte: elaborada pelos autores.

\footnotetext{
6 Dos grãos experimentados, o açúcar foi o que produziu melhor efeito visual, por isso foi escolhido dentre os outros.
} 


\section{IV.2 Versão Eletrônica}

Além da versão mecânica descrita acima, foi construído também um dispositivo eletroóptico com a função de mostrar visualmente as propriedades que caracterizam a onda mecânica sonora da voz humana.

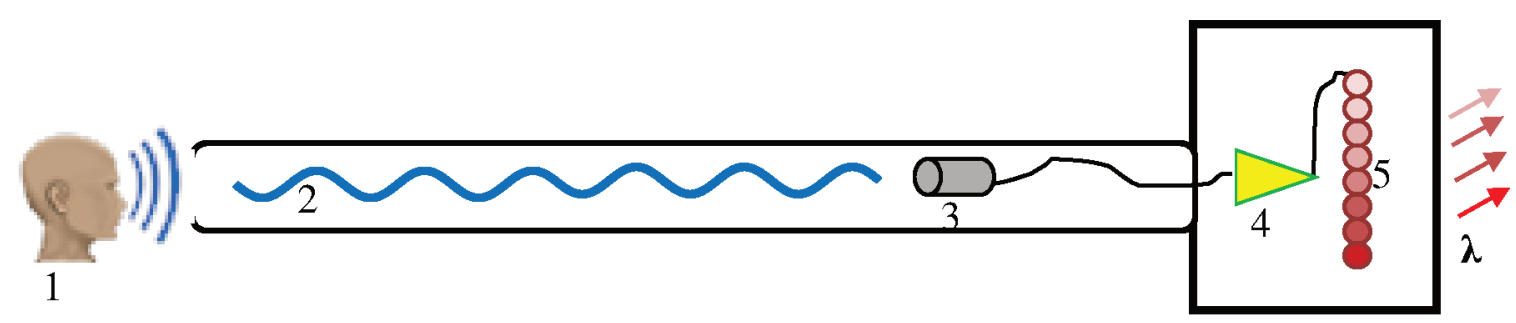

Fig. 5 - Modelo esquemático do dispositivo visualizador óptico da voz humana. $O$ elemento que representa uma pessoa produzindo a voz (1) é a fonte geradora da onda mecânica (2) cuja energia é transformada pelo microfone (3) em energia elétrica e logo condicionada pela circuiteria (4) que tem a função de alimentar o arranjo linear de leds (5) que converte a energia elétrica em luminosa, ascendendo os leds. Fonte: elaborada pelos autores.

Na Fig. 5, é ilustrado o diagrama esquemático do disposivo visualizador óptico da intensidade e frequência da onda mecânica da voz humana. Desde o ponto de vista físico estamos representando a conversão da energia mecânica em energia elétrica e esta última em energia luminosa. Toda a esturutura mecânica é de plástico PVC e está formada por um tubo ressonador de $1 \mathrm{~m}$ de comprimento e $0,08 \mathrm{~m}$ de diâmetro, unido a uma caixa retangular porta circuito e dos leds de dimensões $(0,15$ x 0,1$) \mathrm{m}$. O elemento que representa uma pessoa produzindo a voz é a fonte geradora da onda mecânica cuja energia é transformada pelo microfone em energia elétrica e posteriormente condicionada pela circuiteria, que também tem a tarefa de alimentar o arranjo linear de leds. Finalmente, os leds são responsáveis por converter a energia elétrica que os alimentam em energia luminosa, com valores de intensidade e frequência da onda eletromagnética da luz visível proporcionais à amplitude e à frequência das ondas mecânicas da voz. Estes representam as bases físicas para representar visualmente (através de ondas eletromagnéticas do visível) as ondas mecânicas da voz.

Na Fig. 6 é mostrada uma foto do aparato eletrônico construído mostrando a luminosidade correspondente às ondas sonoras produzidas pela voz. O principal componente do dispositivo é o circuito integrado modelo LM3915, ver Fig. 7, responsvél pelo condicionamento dos sinais elétricos que alimentarão os leds para uma potência de $30 \mathrm{~dB}$. O circuito apresenta um controle de ganho automático permitindo que o sistema seja muito sensível a baixos níveis de ruído e ao mesmo tempo aumenta sua potência em 20dB. Os LEDs foram alimentados com $26 \mathrm{~mA}$ cada um com o controle de brilho no máximo. O circuito tem um interruptor para selecionar os modos de operação: um ponto móvel de luz, ou uma barra mudando o comprimento dos LEDs iluminados. No primeiro caso o maior brilho representa maior amplitude da onda mecânica da voz e a maior pulsação dos leds representa maior 
conteúdo de harmônicos da voz. No segundo modo de operação, observamos que o maior comprimento da barra de leds acesos significa maior amplitude da onda mecânica e a maior frequência da voz representa maior velocidade de criação da barra de luz.

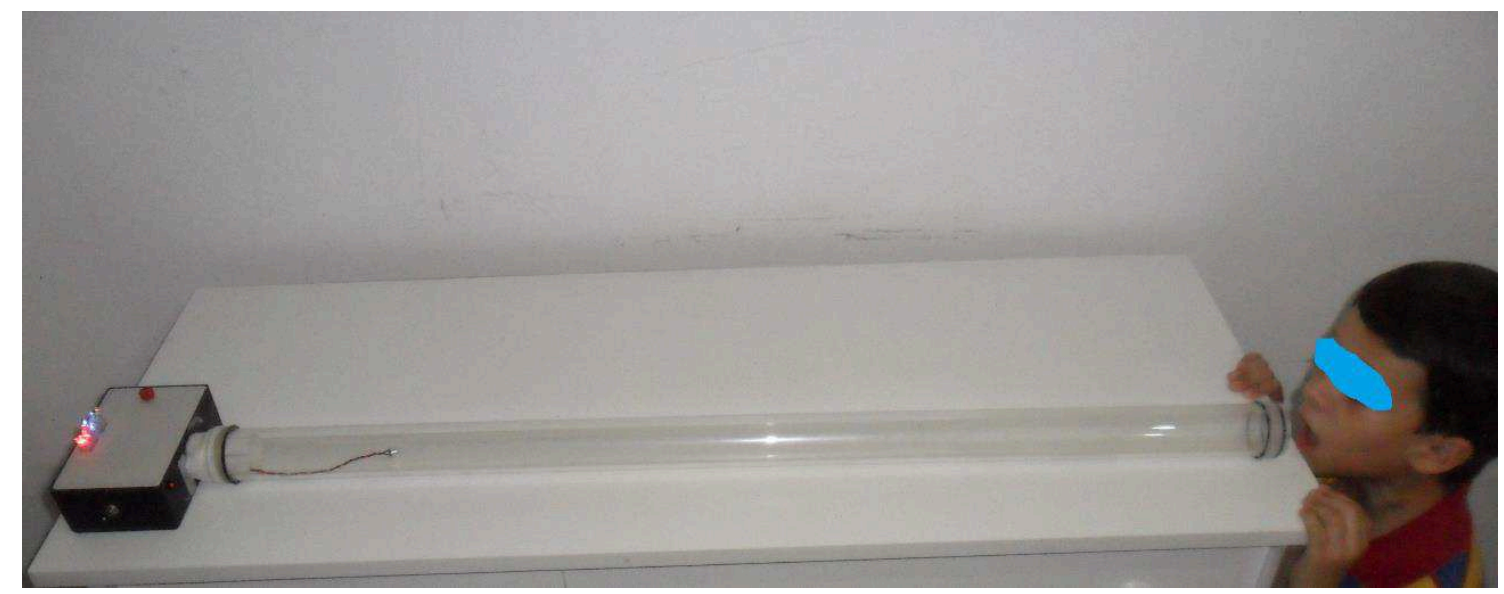

Fig. 6 - Fotografia do aparato eletrônico construído mostrando a luminosidade correspondente às ondas sonoras produzidas pela voz. A criança é filha de um dos autores e está apenas representando por onde o som é emitido. Fonte: elaborada pelos autores.

Na Fig. 7 é mostrado o circuito construído com todos os componentes eletrônicos usados. Como podemos ver, a etapa de alimentação envolve a possibilidade do uso de baterias recarregáveis ou uso direto de alimentação usando um adaptador de tensão de AC para DC de 9V. O funcionamento da circuitaria de condicionamento (processamento analógico) começa pela alimentação do microfone de eletreto com carga R1, usando um regulador de tensão modelo 7805. O microfone funciona como um transdutor de som (a voz) e converte a energia mecânica em energia elétrica. $O$ sinal elétrico depois passa por uma etapa de amplificação inicial através do primeiro amplificador (ICA1) o qual faz parte de um pré-amplificador de áudio com um ganho fixo de 101 vezes. Depois o sinal é conetado à entrada negativa do segundo amplificador com ganho de 1,8 vezes e sua saída concetada à terra é usada como um driver retificador. Cada vez que o sinal alterna para valores negativos em relação ao terra na sua saída drenará valores positivos.

Posteriormente encontramos três transistores modelo 2N3904 os quais estão configurados como seguidores de emissor. Especificamente, o transistor Q1 está dentro de um laço de retroalimentação negativa do segundo amplificador operacional (ICA2) funcionando como um gerador de tensão de referência para os outros dois transistores, ajudando-os a lograr uma melhor compensação mutua. O transistor Q2 seguidor de emissor carrega rapidamente C8 que descarrega mais lentamente em R13 e é usado como um detector de picos. O transistor Q3 é o controle do ganho automático de até 10 vezes. É também um detector de pico, mas tem tem- 

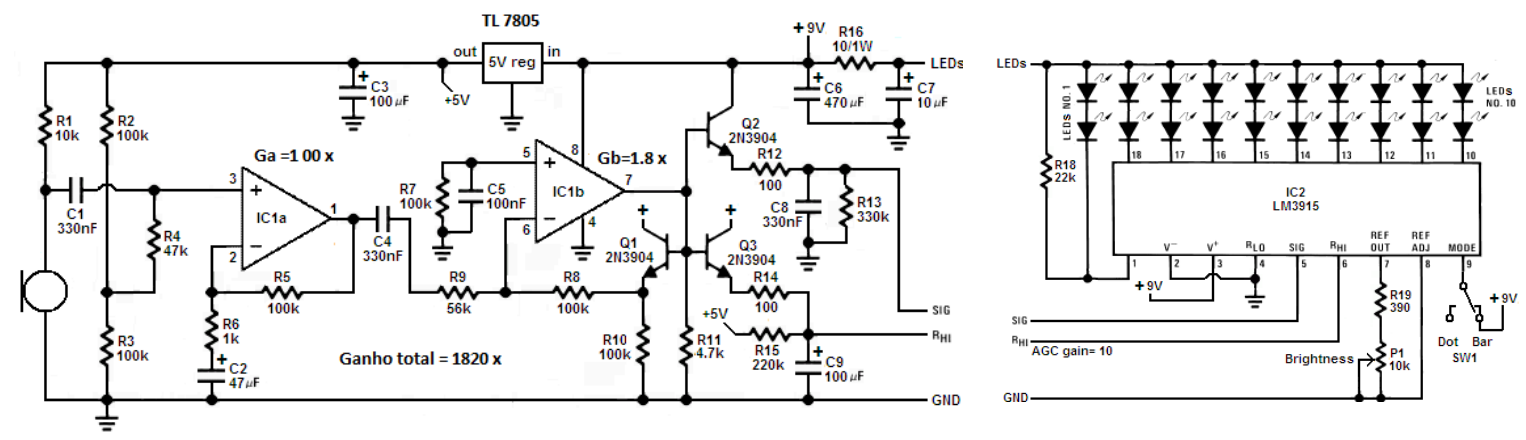

Fig. 7 - Esquema do circuito montado. É composto por uma etapa de alimentação, um microfone de eletreto funcionando como transdutor de som em tensão. Uma etapa inicial de amplificação de aproximadamente 100 vezes, conectada com outra etapa de ganho automático que fornece o sinal ao principal circuito integrado do dispositivo o CI LM3915, o qual é responsável por alimentar de forma automática e apropriada o conjunto de 10 leds, os quais convertem a energia elétrica em energia luminosa. Fonte: elaborada pelos autores.

pos de carga e descarga mais lento. Na saída deste transistor temos o sinal elétrico (SIG) que alimenta os resistores escadas dos comparadores (através do pino 5) do CI LM3915 para determinar quão sensível o sistema é, na detecção do som. O resistor R15 é um divisor da tensão de $+5 \mathrm{~V}$ com a resistência de escada total de $25 \mathrm{~K} \Omega$ e fornece ao valor máximo desta resistência um valor de tensão de $+0,51 \mathrm{~V}$ quando é detectado um nível de ruído de som muito baixo. Sons altos provocam que Q3 alimente a parte superior das resistências de escada com $+5,1 \mathrm{~V}$ para a redução da sensibilidade do dispositivo. O LM3915 regula a corrente que alimenta os LEDs, portanto não precisa de resistores limitadores de corrente. No pino 9 do LM3915 pode ser escolhido o modo de funcionamento do sistema, isto é, um ponto deslizante ou uma barra. Neste último modo com todos os LEDs acesos o CI LM3915 fica quente, por isso precisamos de um resistor R16 de $10 \Omega / 1 \mathrm{~W}$ para dissipar o calor. O potenciômetro $\mathrm{P} 1$ de $10 \mathrm{k} \Omega$ é usado para alterar o brilho dos leds. O ganho total do sistema é da ordem de 1800 vezes.

\section{Perspectiva teórica de uso didático dos experimentos}

Conforme afirmam Stamovlasis et al. (2006), uma das áreas mais férteis da pesquisa em ensino nas últimas décadas são aquelas voltadas para investigar as estratégias de ensino desenvolvidas de modo a promover atividades em que os alunos são conduzidos a trabalhar em pequenos grupos com vistas a compartilhar determinadas metas de aprendizagem, como é o caso das atividades experimentais. Os resultados desta linha de pesquisa têm propiciado evidências significativas que indicam a eficácia deste tipo de estratégia, no que diz respeito às performances dos alunos, quando comparadas com estratégias focadas em atividades individuais. Os autores ainda acentuam que as estratégias que promovem atividades em grupos têm sido 
amplamente utilizadas em salas de aula e com uma grande diversidade de maneiras em todos os níveis de ensino.

As estratégias de ensino voltadas para a promoção de atividades laboratoriais em grupos, de um modo geral, são embasadas em teorias psicológicas, tais como a teoria de Lev Vigotski que concebia a ideia de que o conhecimento é construído pelo sujeito através de um processo de interação social (STAMOVLASIS et al., 2006; REGO, 2000; VIGOTSKI, 1934/2001). Segundo esta visão, o Homem é compreendido como um ser social que interfere e é influenciado pelo meio através da sua interação com o mesmo e, assim, se desenvolve e se constitui como Homem. As ações que os seres humanos desenvolvem em grupos sociais são reconstruídas internamente produzindo desenvolvimento e conhecimento no indivíduo, ou seja, há um processo de transformação que vai desde processos externos, intersubjetivos, a um processo interno, intrasubjetivo, logo na direção do social para o individual (REGO, 2000). Desta forma, "na perspectiva de Vigotski, construir conhecimentos implica uma ação partilhada, já que é através dos outros que as relações entre sujeito e objeto de conhecimento são estabelecidas" (REGO, 2000, p. 107).

Segundo Vigotski, é dos processos de interação social que se originam, portanto, o desenvolvimento mental e a aprendizagem. Assim, ele formula o conceito de Zona de Desenvolvimento Proximal (ZDP) que é "a distância entre o nível de desenvolvimento real, que se costuma determinar através da solução independente de problemas, e o nível de desenvolvimento potencial, determinado através da solução de problemas sob a orientação de um adulto ou em colaboração com companheiros mais capazes" (VIGOTSKI, 2000, p. 112).

Este conceito estabelece que a aprendizagem depende externamente do desenvolvimento mental e está sempre atrás deste, ou seja, somente se consegue atingir determinado estágio de aprendizagem depois que se conseguir atingir determinado estágio do desenvolvimento em grau correspondente, grau necessário para que a aprendizagem seja possível. Nas palavras do próprio Vigotski, “a aprendizagem é caudatária do desenvolvimento. O desenvolvimento deve completar determinados ciclos, deve concluir determinados estágios para que a aprendizagem se torne viável" (VIGOTSKI, 1934/2001, p. 298). E a interação do sujeito com os outros (colegas e professor, por exemplo), através de atividades coletivas - como é o caso das atividades de laboratório didático - é fundamental "tanto na criação do desenvolvimento proximal quanto na transformação do desenvolvimento proximal em real” (GÓES, 2001, p. 82), ou seja, na transformação dos aspectos intersubjetivos em intrasubjetivos.

Assumindo esta perspectiva dentro do contexto educacional, se é inevitavelmente conduzido a uma direção na qual, para que haja desenvolvimento cognitivo e conhecimento (aprendizagem) por parte dos alunos de forma satisfatória, é necessário o envolvimento destes em atividades de laboratório didático de modo a promover uma interação social entre os sujeitos (alunos-alunos e alunos-professor) para a construção e compartilhamento de conhecimentos através do diálogo, discussão, confronto de ideias, colaboração e compartilhamento de funções e responsabilidades. Esta interação, para o caso dos alunos surdos, propicia um maior estímulo 
à participação dos mesmos nas atividades didáticas levando-os a integrarem nas práticas laboratoriais seja através da oralidade, ou da linguagem de sinais, o que resulta em uma maior inserção social destes sujeitos no contexto da sala de aula e a um melhor aproveitamento em termos de aprendizagem, corroborando a perspectiva da teoria compensatória de Vigotski. Dentro dessa perspectiva, a Tecnologia Assistiva que foi desenvolvida e aqui apresentada, na forma de um experimento didático em duas versões para o ensino de ondas sonoras, aparece como uma contribuição para o ensino deste tema da física - assumindo uma visão vigotskiana de aprendizagem - voltado para propiciar uma maior integração entre alunos surdos e ouvintes dentro da sala de aula.

\section{Considerações finais}

Como afirma Vigotski, o que inibe o desenvolvimento do sujeito surdo não é seu estado deficitário, mas sim as consequências sociais que a ele está ligado, ou seja, o que falta a eles é um trabalho pedagógico que esteja voltado para sua especificidade, evidenciada pela língua de sinais e que saiba aproveitar o canal visual como uma maneira de proporcionar o desenvolvimento psicológico da criança surda. Deste modo, para que o Surdo possa desenvolver-se adequadamente, se faz necessário um trabalho educacional voltado para a compensação do déficit e não para a correção da surdez.

Permanece, então, a questão da importância do desenvolvimento dos recursos didáticos, pois estes materiais têm de ser significativos para estes alunos. O professor deve buscar novas formas de ensinar, levando sempre em consideração a realidade do aluno e contextualizar o assunto abordado para que o mesmo encontre correspondência com o modo como percebe o mundo.

Os experimentos (mecânico e eletrônico) podem exercer um papel importante na compreensão do conceito de ondas sonoras pelos alunos surdos, bem como pelos alunos ouvintes. No que se refere ao aluno surdo, em qualquer um desses experimentos, ele pode emitir o som e terá mais condições de perceber que sua propagação vai desde as suas cordas vocais (que sentirá vibrar) até a outra extremidade do aparelho (a cabaça, no caso do experimento mecânico e os LEDs no caso do experimento eletrônico) onde se configuram os diferentes modos de vibração e o aluno terá uma percepção visual da onda sonora. Já para o aluno ouvinte, os experimentos servirão como um material auxiliar, além de ser grande valia para a interação social dos referidos alunos, uma vez que permitem a integração de surdos e ouvintes para cumprir o mesmo objetivo de compreender a produção de ondas sonoras a partir da voz emitida por ambos os grupos. Outra grande vantagem consiste no fato que eles foram confeccionados, totalmente, com materiais de baixo custo.

Vale salientar que se trata de experimentos ainda não avaliados em situações reais de sala de aula, portanto somente com a implementação de uma proposta didática previamente elaborada que seja aplicada em sala de aula, com a presença de alunos surdos e ouvintes, é que 
será possível avaliar os benefícios, bem como as limitações, em termos de compreensão conceitual e de integração social dos alunos, desta Tecnologia Assistiva apresentada no presente trabalho na forma de experimento didático. Este é o próximo passo a ser desenvolvido pelos autores.

\section{Referências}

BRASIL. Decreto $\mathbf{n}^{\mathbf{0}}$. 5.626, de 22 de Dezembro de 2005. Regulamenta a Lei no 10.436, de 24 de abril de 2002, que dispõe sobre a Língua Brasileira de Sinais -Libras.

BRASIL. Lei no 10.098 de 19 de Dezembro de 2002. Brasília 2002.

BRASIL. Decreto no 3.956, de 8 de outubro de 2001. Promulga a Convenção Interamericana para a Eliminação de Todas as Formas de Discriminação contra as Pessoas Portadoras de Deficiência. Brasília, DF, 2001. Disponível em: <http://www.planalto.gov.br/ccivil_03/decreto/2001/d3956.htm>. Acesso em: 23 ago. 2012.

BRASIL. Lei $\mathbf{n}^{\mathbf{0}}$ 10.436, de 24 de abril de 2002. Dispõe sobre a Língua Brasileira de Sinais Libras e dá outras providências. Brasília, DF, 2002. Disponível em: <http://www.planalto.gov.br/ccivil_03/leis/2002/110436.htm>. Acesso em: 23 ago. 2012.

BRASIL. Constituição (1988). Capítulo III da educação, da cultura e do desporto. Seção I da educação. Artigo 205 e 206. Disponível em: <http://www.planalto.gov.br/ccivil_03/constituicao/constituicao.htm>. Acesso em: 23 ago. 2012.

CAT, 2007c. Ata da Reunião VII, de dezembro de 2007, Comitê de Ajudas Técnicas, Secretaria Especial dos Direitos Humanos da Presidência da República (CORDE/SEDH/PR). Disponível em: <http://www.mj.gov.br/sedh/ct/corde/dpdh/corde/Comitê\%20de\%20Ajudas\%20Técnicas/Ata_VII_Reunião_do_Comite_de_Ajudas_Técnicas.doc> Acesso em: 05 jan. 2011.

DURAN, J. E. R. Biofísica: Conceitos e Aplicações. 2. ed. São Paulo: Pearson Prentice Hall, 2011.

GALVÃO, T. A. Tecnologia Assistiva para uma Escola Inclusiva: Apropriação, demanda e perspectivas. 346p. 2009. Tese (doutorado) - Faculdade de Educação, Universidade Federal da Bahia.

GÓES, M. C. R. A Construção de Conhecimentos e o Conceito de Zona de Desenvolvimento Proximal. In: MORTIMER, E. F.; SMOLKA, A. L. B. (Orgs.). Linguagem, cultura e cognição: Reflexões para o ensino e a sala de aula. Belo Horizonte: Autêntica, 2001. p. 77-88.

GOLDFELD, M. A Criança Surda - Linguagem e Cognição numa Perspectiva Sociointeracionista. 2. ed. São Paulo: Plexus, 2002. 
HONORA, M.; FRIZANCO, M. L. Esclarecendo as Deficiências - Aspectos Teóricos e Práticos para Contribuir com uma Sociedade Inclusiva. São Paulo: Ciranda Cultural Editora e Distribuidora Ltda., 2008.

IBGE, Censo 2000. Disponível em: <http://www.ibge.gov.br/censo/> Acesso em: 25 ago. 2011.

MOURA, M. C. O surdo: Caminhos para uma Nova Identidade. Rio de Janeiro: Revinter, 2000.

NASCIMENTO, L. C. R. Um pouco mais da história da educação dos surdos, segundo Ferdinand Berthier. ETD - Educação Temática Digital, Campinas, v. 7, n .2, p. 255-265, jun. 2006.

PEREIRA, R. C. Surdez - Aquisição de Linguagem e Inclusão Social. Rio de Janeiro: Revinter, 2008.

REGO, T. C. R. A Origem da Singularidade Humana na Visão dos Educadores. Cadernos CEDES, v. 35, 2000.

SACKS, O. Vendo Vozes - Uma Viagem ao Mundo dos Surdos. São Paulo: Companhia das Letras, 2010.

STAMOVLASIS, D.; DIMOS, A.; TSAPARLISA, G. Study of group interaction processes in learning lower secondary Physics. Journal of Research in Science Teaching, v. 43, n. 6, 556576, 2006.

VALADARES, E. C. Física Mais que Divertida. 2. ed. Belo Horizonte: Editora UFMG, 2002.

VIGOTSKI, L. Obras Escogidas V. Madrid: Editorial Pedagógica, 1997.

VIGOTSKI, L. A Construção do Pensamento e da Linguagem. Tradução: Paulo Bezerra. São Paulo: Martins Fontes, 1934/2001.

VIGOTSKI, L. A Formação Social da Mente. São Paulo: Martins Fontes, 2000.

VIVAS, D. B. P. Ensino de Física para Surdos. 2012. Trabalho de Conclusão de Curso. (Graduação em Física) - Universidade Estadual de Feira de Santana. Orientador: Elder Sales Teixeira, Co-Orientador: Juan Alberto Leyva Cruz.

<http://www.electronics-lab.com/projects/motor_light/002/>. Acesso em: set. 2012. 